Aim of the study: To assess the quality of life in patients treated for breast cancer who were 5 years after diagnosis and were active members of Breast Cancer Self-Help Groups.

Material and methods: The study had a non-randomized, cross-sectional design. We enrolled 167 women who were more than 5 years after mastectomy and were active members of Breast Cancer Self-Help Groups (group A1). As a control group we enrolled 117 women after mastectomy not members of such support groups (group A2). For the evaluation of the quality of life in both groups we used the following standardized questionnaires - EORTC QLQ-C30 and EORTC QLQ-BR23 as well the Mini-MAC scale for the assessment of strategies of coping with disease.

Results: Based on QLQ C30 scores, group $\mathrm{A} 1$ had better emotional functioning $(p=0.0005)$ and a higher general quality of life $(p=0.0259)$, whereas group A2 had better role functioning ( $p=0.0042)$. Based on QLQ BR23 scores, there were statistically significant differences in body image $(p=0.0366)$ and life perspectives $(p=0.0313)$ in favor of group A1. In the control group, there was a greater use of destructive coping strategies and anxious preoccupation $(p=0.1957)$.

Conclusions: Membership in Amazon groups improves functioning in breast cancer patients that can also extend into a five-year period after treatment completion.

Key words: breast cancer, Self-Help Groups, quality of life, mastectomy, standardized questionnaires.

Contemp Oncol (Pozn) 2018; 22 (1): 20-26 DOI: https://doi.org/10.5114/wo.2018.74389

\section{Assessment of quality of life in women five years after breast cancer surgery, members of Breast Cancer Self-Help Groups - non- randomized, cross-sectional study}

\author{
Magdalena Sowa ${ }^{1,2}$, Iwona Głowacka-Mrotek ${ }^{3}$, Ewelina Monastyrska ${ }^{1}$, \\ Tomasz Nowikiewicz ${ }^{1}$, Magdalena Mackiewicz-Milewska ${ }^{3}$, Wojciech Hagner ${ }^{3}$, \\ Wojciech Zegarski ${ }^{1}$
}

\author{
${ }^{1}$ Department of Surgical Oncology, Collegium Medicum of the Nicolaus Copernicus \\ University in Torun, Oncology Center in Bydgoszcz, Poland \\ 2Department of Laser Therapy and Physiotherapy, Collegium Medicum of the Nicolaus \\ Copernicus University in Torun, Poland \\ ${ }^{3}$ Department of Rehabilitation, Collegium Medicum of the Nicolaus Copernicus \\ University in Torun, Poland
}

\section{Introduction}

Breast cancer is the most common cancer type in women in the developed countries, and according to the World Health Organization (WHO), constitutes one of the most important issues for public health. The mainstay of treatment for breast cancer is mastectomy or breast-conserving surgery. Mastectomy causes stress, a feeling of shame as well as depressed mood. These consequences are seen in patients regardless of the time after treatment completion. In addition to physical scaring, patients after breast cancer surgery experience mental trauma. For this reason, it is necessary to study various aspects of quality of life in such patients [1]. According to Antonovsky, cancer, oftentimes being a chronic disease, is one of the critical life events. The diagnosis of breast cancer causes stress, fear and is associated with a multitude of problems requiring adaptation to the disease. This negatively influences the general quality of life [2].

The notion of quality of life was introduced into the medical science in the 1970s. In the recent years, health-related quality of life has gained special interest, which is associated with a holistic approach to the cancer patient. Because of the systematic increase in cancer morbidity, the assessment of quality of life has become an important part of management of cancer patients [3]. WHO defines quality of life as "an individual's perception of their position in life in the context of the culture and value systems in which they live and in relation to their goals, expectations, standards and concerns" [4]. In medical science, quality of life assessment is based on evaluating the problems related to the disease itself as well as to the applied treatment in terms of changes in physical, mental and social functioning, and subjective well-being [5].

Breast Cancer Self-Help Groups play a very important role as support groups for women after breast cancer surgery. Initially, these groups were founded in order to provide mental support and motivation for further treatment to women with breast cancer [6]. Amazon groups are organized by women who were treated for breast cancer. Their tasks include providing information on various methods of rehabilitation as well as on social events such as excursions.

The aim of the study was to assess the quality of life in women after mastectomy, who were active members of Amazon groups. These women 
were compared to similar women who were not members of such groups.

\section{Material and methods}

The study had a non-randomized, cross-sectional design. The study was approved by the Bioethical Committee at the Collegium Medicum in Bydgoszcz (No. 110/2016). Informed consent was obtained from all individual participants included in the study at the time of the survey. We enrolled 167 patients after mastectomy who were active members (at least one meeting per week in the last year) of Breast Cancer Self-Help Groups - group A1). The studied patients were members of Amazon groups in the Kuyavian-Pomeranian Voivodeship. There are 8 such Amazon groups in this Voivodeship with 450 members. Of these 450 members, 200 met the inclusion criteria and 33 did not consent to participate in the study. Therefore, $167 \mathrm{pa}$ tients were included. The control group included 117 women - consecutive patients reporting for follow-up visits at the Center for Oncology in Bydgoszcz from March 2016 to August 2016, who met the necessary inclusion criteria and were not members of Amazon groups. Subjects from the control group completed their questionnaires in a separate room, were accompanied by the researcher throughout the study, and were allowed to ask any questions during their participation.

The control group consisted of 117 women after mastectomy who were not members of such support groups - group A2.

Inclusion criteria:

- patients who had undergone a BCT or mastectomy procedure,

- patients who had had breast surgery 5 years before or earlier,

- patients who had completed their oncological treatment,

- consent to participate in the study.

Exclusion criteria:

- patients undergoing oncological treatment,

- bilateral mastectomy,

- other cancer now or in the past,

- psychiatric diseases,

- obesity (grade III - BMI < 40),

- other ASA IV severe diseases: patients with severe systemic diseases that present constant threat to their lives.

Study design:

- consent to participate in the study,

- data collection - sociodemographic data, clinical data (date of surgery, type of surgery, type of treatment [chemotherapy, hormone therapy, radiotherapy], place of residence, occupation, length of membership in an Amazon group),

- completion of quality of life questionnaires - QLQ-C30 and QLQ-BR23,

- completion of the Mini-MAC scale.

Patients completed the questionnaires on their own after a short demonstration.

\section{Research tools}

EORTC - QLQ-C30 (Questionnaire for Quality of Life Assessment in patients with cancer, version 3.0) - an international, standardized research tool consisting of 5 functional scales, 3 symptomatic scales, a scale for the assessment of general quality of life QLQ and 6 individual items. The questionnaire consists of 30 items and can be used in all patients receiving cancer treatment regardless of cancer type and its location. All scores form the individual parts of the questionnaire range from 0 to 100 points. Higher scores in the functional scales mean better functioning.

EORTC - QLQ-BR23 (quality of life questionnaire breast cancer) - an extension to the QLQ-C30. It consists of 23 items and was created specifically for breast cancer patients. QLQ-BR23 covers the following areas - side effects of treatment, body image, sexual functioning, arm symptoms, breast symptoms, and additional individual items. All scores from the individual parts of the questionnaire range from 1 to 4 with higher scores corresponding to worse functioning.

Mini-MAC scale (Polish version) - consists of 29 items and measures four strategies of coping with cancer - anxious preoccupation, helplessness - hopelessness (destructive strategies), fighting spirit and positive redefinition (constructive strategies). Scores are computed for each strategy separately and higher scores correspond to higher intensities of respective strategies.

\section{Statistical analysis}

We performed the statistical analysis with the use of the PQStat ver. 1.6 software. The $t$-test was used for comparing age between the study groups. The remaining comparisons of quantitative variables between the study groups were performed with the Mann-Whitney U-test.

Qualitative variables were compared between the study groups with the $\chi^{2}$ test.

$P$-value of less that 0.05 was considered significant, and highly significant if it was less than 0.001.

\section{Results}

We did not find significant differences between groups in terms of age, number of family members, education, place of residence, or type of treatment $(\mathrm{CHTH}, \mathrm{HTH})$.

We found statistically significant differences between the studied groups in occupation and adjuvant treatment $(\mathrm{CHTH}+\mathrm{RTH}, \mathrm{RTH})$ - women from the A2 group were more frequently employed and had a lower frequency of adjuvant treatment than women from the A1 group. Sociodemographic and clinical data of the studied groups are presented in Table 1. We would like to highlight that all information regarding the history of neoadjuvant and adjuvant treatment was obtained from patient interviews and was not verified in patients' medical histories.

Table 2 presents QLQ-C30 quality of life scores in both study groups (A1 and A2). The general quality of life scores were significantly higher in group $A 1$, corresponding to a better quality of life $(p=0.0259)$. Similarly, patients in group $\mathrm{A} 1$ had higher scores in emotional functioning and this difference was highly significant $(p=0.0005)$. Patients 
Table 1. Sociodemographic and clinical characteristics of the study groups (A1 vs. A2) and between-group differences

\begin{tabular}{|c|c|c|c|c|c|}
\hline \multicolumn{2}{|l|}{ Demographic data } & A1 $(n=167)$ & \multicolumn{3}{|c|}{$\mathrm{A} 2(n=117)$} \\
\hline \multicolumn{2}{|l|}{ Age, mean year (SD) } & \multicolumn{2}{|c|}{$63.67(8.41)$} & \multicolumn{2}{|c|}{$63.41(7.38)$} \\
\hline \multicolumn{2}{|c|}{ Student $t$-test/Mann-Whitney U-test } & \multicolumn{4}{|c|}{$t=0.26, p=0.7955$} \\
\hline \multicolumn{2}{|c|}{ Number of family members (SD) } & \multicolumn{2}{|c|}{$2.17(1.04)$} & \multicolumn{2}{|c|}{$2.56(2.21)$} \\
\hline \multirow{2}{*}{\multicolumn{2}{|c|}{ Student $t$-test/Mann-Whitney U-test }} & \multicolumn{4}{|c|}{$Z=1.22, p=0.2212$} \\
\hline & & Number & $\%$ & Number & $\%$ \\
\hline \multirow[t]{6}{*}{ Education } & elementary & 5 & 3.11 & 8 & 6.84 \\
\hline & middle & 116 & 72.05 & 71 & 60.68 \\
\hline & high & 40 & 24.84 & 38 & 32.48 \\
\hline & $\chi^{2}$ & \multicolumn{4}{|c|}{4.73} \\
\hline & degrees of freedom & \multicolumn{4}{|c|}{2} \\
\hline & $p$-value & \multicolumn{4}{|c|}{0.0941} \\
\hline \multirow[t]{6}{*}{ Residency } & village & 29 & 18.01 & 27 & 23.08 \\
\hline & town up to 100,000 & 57 & 35.40 & 44 & 37.61 \\
\hline & town $>100,000$ & 75 & 46.58 & 46 & 39.32 \\
\hline & $\chi^{2}$ & \multicolumn{4}{|c|}{1.78} \\
\hline & degrees of freedom & \multicolumn{4}{|c|}{2} \\
\hline & $p$-value & \multicolumn{4}{|c|}{0.4116} \\
\hline \multirow[t]{6}{*}{ Occupation } & full-time & 19 & 11.80 & 27 & 23.08 \\
\hline & farming & 4 & 2.48 & 1 & 0.85 \\
\hline & retirement & 114 & 85.72 & 62 & 76.07 \\
\hline & $\chi^{2}$ & \multicolumn{4}{|c|}{12.07} \\
\hline & degrees of freedom & \multicolumn{4}{|c|}{3} \\
\hline & $p$-value & \multicolumn{4}{|c|}{0.0071} \\
\hline \multirow[t]{16}{*}{ Adjuvant therapy, $n$ (\%) } & CHTH, RTH & 73 & 59.8 & 70 & 45.3 \\
\hline & $\chi^{2}$ & \multicolumn{4}{|c|}{5.69} \\
\hline & degrees of freedom & & & & \\
\hline & $p$-value & & & & \\
\hline & $\mathrm{CHTH}$ & 37 & 22.9 & 22 & 18.0 \\
\hline & $\chi^{2}$ & & & & \\
\hline & degrees of freedom & & & & \\
\hline & $p$-value & & & & \\
\hline & RTH & 29 & 18 & 11 & 9.4 \\
\hline & $\chi^{2}$ & & & & \\
\hline & degrees of freedom & & & & \\
\hline & $p$-value & & & & \\
\hline & HTH & 83 & 51.5 & 59 & 50.42 \\
\hline & $\chi^{2}$ & & & & \\
\hline & degrees of freedom & & & & \\
\hline & $p$-value & & & & \\
\hline
\end{tabular}

A1 - members of Amazon groups; A2 - control group; $p$ - statistical significance; CHTH - chemotherapy; RTH - radiotherapy; HTH - hormone therapy

in group A2 had significantly higher scores in role functioning $(p=0.0042)$.

There were no significant differences between the study groups in terms of physical functioning, cognitive functioning and social functioning $(p>0.05)$.

With the use of the QLQ-BR 23 questionnaire, the following variables were measured - body image, sexual functioning, sexual pleasure, life perspectives, treatment side effects, breast symptoms, arm symptoms, and stress related to hair loss (Table 3). We compared the scores between the study groups. We found statistically significant differences in body image $(p=0.0366)$ and life perspectives ( $p=0.0313$ ), both in favor of members of Amazon groups. Moreover, breast symptoms were more intense in 
Table 2. Quality of life in both groups (A1 and A2) and between-group comparisons (A1 vs. A2) regarding the scores of the QLQ-C30 questionnaire

\begin{tabular}{|c|c|c|c|c|}
\hline $\begin{array}{l}\text { EORTC QLQ C-30 } \\
\text { Functional scales } \\
\text { (best score }-100 \text { points) }\end{array}$ & Study groups & Arithmetic mean & Standard deviation & $\begin{array}{c}\text { Mann-Whitney } \\
U \text {-test }\end{array}$ \\
\hline \multirow[t]{2}{*}{ Physical functioning (1-5) } & A2 & 68.49 & 24.12 & \multirow{2}{*}{$\begin{array}{c}Z=0.95 \\
p=0.3422\end{array}$} \\
\hline & $\mathrm{A} 1$ & 66.05 & 24.82 & \\
\hline \multirow[t]{2}{*}{ Role functioning $(6,7)$} & A2 & 84.62 & 19.84 & \multirow{2}{*}{$\begin{array}{c}Z=2.87 \\
p=0.0042\end{array}$} \\
\hline & $\mathrm{A} 1$ & 77.74 & 21.81 & \\
\hline \multirow[t]{2}{*}{ Emotional functioning (21-24) } & A2 & 64.46 & 20.60 & \multirow{2}{*}{$\begin{array}{c}Z=3.48 \\
p=0.0005\end{array}$} \\
\hline & $\mathrm{A} 1$ & 73.34 & 24.35 & \\
\hline \multirow[t]{2}{*}{ Cognitive functioning (20-25) } & $\mathrm{A} 2$ & 69.94 & 23.29 & \multirow{2}{*}{$\begin{array}{c}Z=1.19 \\
p=0.2346\end{array}$} \\
\hline & $\mathrm{A} 1$ & 72.67 & 24.69 & \\
\hline \multirow[t]{2}{*}{ Social functioning $(26,27)$} & $\mathrm{A} 2$ & 78.06 & 20.91 & \multirow{2}{*}{$\begin{array}{c}Z=0.89 \\
p=0.3724\end{array}$} \\
\hline & $\mathrm{A} 1$ & 76.54 & 19.44 & \\
\hline \multirow[t]{2}{*}{ General quality of life $(29,30)$} & $\mathrm{A} 2$ & 38.10 & 14.75 & \multirow{2}{*}{$\begin{array}{c}Z=2.23 \\
p=0.0259\end{array}$} \\
\hline & $\mathrm{A} 1$ & 41.74 & 16.47 & \\
\hline
\end{tabular}

EORTC QLQ-C30 - European Organization for Research and Treatment of Cancer Quality of Life Questionnaire; A1 - members of Amazon groups; A2 - control group, $p$-statistical significance

Table 3. Quality of life in both study groups (A1 and A2) and between-group comparisons regarding the scores of the QLQ-BR23 questionnaire

\begin{tabular}{|c|c|c|c|c|}
\hline $\begin{array}{l}\text { EORTC } \\
\text { QLQ-BR23 } \\
\text { Symptomatic scales } \\
\text { (best score }-1 \text { point) }\end{array}$ & Study groups & Arithmetic mean & Standard deviation & $\begin{array}{c}\text { Mann-Whitney } \\
\text { U-test }\end{array}$ \\
\hline \multirow[t]{2}{*}{ Body image (9-12) } & $\mathrm{A} 2$ & 2.19 & 0.78 & \multirow{2}{*}{$\begin{array}{c}Z=2.09 \\
p=0.0366\end{array}$} \\
\hline & A1 & 2.01 & 0.79 & \\
\hline \multirow[t]{2}{*}{ Sexual functioning $(14,15)$} & $\mathrm{A} 2$ & 1.63 & 0.74 & \multirow{2}{*}{$\begin{array}{c}Z=0.80 \\
p=0.4223\end{array}$} \\
\hline & $\mathrm{A} 1$ & 1.55 & 0.71 & \\
\hline \multirow[t]{2}{*}{ Sexual pleasure 16} & A2 & 2.54 & 0.66 & \multirow{2}{*}{$\begin{array}{c}Z=1.19 \\
p=0.2320\end{array}$} \\
\hline & $\mathrm{A} 1$ & 2.39 & 0.68 & \\
\hline \multirow[t]{2}{*}{ Life perspectives 13} & A2 & 2.78 & 0.90 & \multirow{2}{*}{$\begin{array}{c}Z=2.15 \\
p=0.0313\end{array}$} \\
\hline & A1 & 2.53 & 0.96 & \\
\hline \multirow[t]{2}{*}{ Treatment side effects $(1-4,6,7,8)$} & $\mathrm{A} 2$ & 1.73 & 0.52 & \multirow{2}{*}{$\begin{array}{c}Z=1.63 \\
p=0.1027\end{array}$} \\
\hline & A1 & 1.81 & 0.49 & \\
\hline \multirow[t]{2}{*}{ Breast symptoms (20-23) } & $\mathrm{A} 2$ & 1.41 & 0.55 & \multirow{2}{*}{$\begin{array}{c}Z=3.24 \\
p=0.0012\end{array}$} \\
\hline & $\mathrm{A} 1$ & 1.60 & 0.59 & \\
\hline \multirow[t]{2}{*}{ Arm symptoms $(17,18,19)$} & $\mathrm{A} 2$ & 2.09 & 0.72 & \multirow{2}{*}{$\begin{array}{c}Z=1.39 \\
p=0.1643\end{array}$} \\
\hline & A1 & 2.20 & 0.68 & \\
\hline \multirow[t]{2}{*}{ Stress related to hair loss 5} & A2 & 2.26 & 0.94 & \multirow{2}{*}{$\begin{array}{c}Z=0.61 \\
p=0.5445\end{array}$} \\
\hline & $\mathrm{A} 1$ & 2.37 & 0.97 & \\
\hline
\end{tabular}

EORTC QLQ-BR23 - European Organization for Research and Treatment of Cancer Quality of Life Questionnaire Breast Cancer module; A1 - members of Amazon groups, A2 - control group; $p$ - statistical significance 
members of Amazon groups as compared to the control group. This difference was highly significant $(p=0.0012$; Table 3).

There were no statistically significant differences between the study groups in the following scales - sexual functioning, sexual pleasure, treatment side effects, arm symptoms, stress related to hair loss ( $p>0.05)$.

We assessed coping strategies with the use of the MiniMAC scale on the following sub-scales - anxious preoccupation, fighting spirit, helplessness - hopelessness, positive redefinition. Patients in group A2 had higher scores in the anxious preoccupation scale as compared to group A1. This difference was statistically significant ( $p=0.0284$ ). Although patients in group A2 had higher scores in the helplessness - hopelessness sub-scale, this difference was not significant ( $p=0.1957$ ). Although patients in group A1 had higher scores in scales assessing the constructive coping strategies (fighting spirit and positive redefinition), this difference was not statistically significant $(p>0.05$; Table 4).

\section{Discussion}

In this study we used standardized questionnaires, namely, EORTC QLQ-C30, EORTC QLQ-C29 and the MiniMAC scale. This allowed us to compare our results with studies on the quality of life in breast cancer patients performed earlier. Additional observations were made possible by dividing breast cancer patients into those who were members of support groups (Amazon groups) or otherwise, and by including patients with a long-term follow-up (5-10 years after surgery). Our results clearly indicate that members of Amazon groups experience significant benefits. These patients had higher scores in emotional functioning, general quality of life, body image and life perspectives. Moreover, patients who were not members of Amazon groups had greater emotional problems, as measured by the Mini-MAC scale.

According to de Boer et al., patients treated for breast cancer usually resign from work. This results primarily from a long and debilitating treatment [7]. Although in our study women in the control group were significantly more active at work (23.08\% vs. $11.8 \%, p=0.0071$ ), they did not have better quality of life scores except for the work sub- scale. As in previous studies, patients with higher education level, who are satisfied with their work, showed a better quality of life $[8,9]$.

In our study, we found that members of Amazon groups had better scores in general quality of life, including emotional functioning as compared to the control group. The between-group differences were highly statistically significant. Similar observations were made by other authors $[10,11]$.

After treatment completion, there is a difference between the situation of women treated with mastectomy compared to those after breast-conserving surgery [12]. Because of a greater physical scaring, patients after mastectomy have various problems with their body image [1214]. We found that members of Amazon groups had better scores in the scales of body image and life perspectives than the control group, as measured by the QLQ-BR23 questionnaire.

Factors that can contribute to a decreased quality of life in patients after mastectomy include physical symptoms such as restriction of movement in the shoulder or lymphedema of the arm. Such physical limitations are common reasons for job absence [15]. In our group, physical symptoms were present in patients even five years after diagnosis and were more pronounced in members of Amazon groups.

We used the Mini-MAC scale for the assessment of coping strategies. In both study groups, the constructive coping strategies prevailed. This is in line with previous studies that found that disease-related stress decreases with time after treatment completion $[16,17]$. There was a statistically significant difference between the study groups in anxious preoccupation, which was more pronounced in the control group. In contrast, members of Amazon groups were able to use support of other people from the group. Consequently, members of Amazon groups used this particular coping strategy less frequently. Based on clinical trials, breast cancer patients after mastectomy who use constructive coping strategies had better survival rates $[18,19]$.

As already established in previous research, the environments created by members of support groups for breast cancer patients provide a friendly milieu. They are

Table 4. Coping strategies in both study groups (A1 and A2) and between-group comparisons regarding the scores of the Mini-MAC scale

\begin{tabular}{|c|c|c|c|c|}
\hline Mini-MAC scale coping with disease & Study group & Arithmetic mean & Standard deviation & Mann-Whitney $U$-test \\
\hline \multirow[t]{2}{*}{ Anxious preoccupation } & $\mathrm{A} 2$ & 2.28 & 0.63 & \multirow{2}{*}{$\begin{array}{c}Z=2.19 \\
p=0.0284\end{array}$} \\
\hline & $\mathrm{A} 1$ & 2.12 & 0.64 & \\
\hline \multirow[t]{2}{*}{ Fighting spirit } & $A 2$ & 3.26 & 0.42 & \multirow{2}{*}{$\begin{array}{c}Z=0.40 \\
p=0.6883\end{array}$} \\
\hline & $\mathrm{A} 1$ & 3.29 & 0.44 & \\
\hline \multirow[t]{2}{*}{ Helplessness - hopelessness } & $\mathrm{A} 2$ & 1.86 & 0.55 & \multirow{2}{*}{$\begin{array}{c}Z=1.29 \\
p=0.1957\end{array}$} \\
\hline & A1 & 1.77 & 0.48 & \\
\hline \multirow[t]{2}{*}{ Positive redefinition } & $\mathrm{A} 2$ & 3.12 & 0.42 & \multirow{2}{*}{$\begin{array}{c}Z=1.28 \\
p=0.2017\end{array}$} \\
\hline & $\mathrm{A} 1$ & 3.16 & 0.47 & \\
\hline
\end{tabular}

A1 - members of Amazon groups; A2 - control group; $p$ - statistical significance 
places for a safe exchange of experiences and provide unconditional acceptance [20, 21].

The characteristic feature of our study was that it was performed among patients long after completion of cancer treatment. Studies assessing the effects of early intervention in support groups among patients treated for breast cancer often do not take into account the differences in quality of life between patients who are members of support groups and other patients [22]. Other studies assessed the role of support groups in patients just after diagnosis [23]. The research performed so far suggests that breast cancer patients benefit from support groups regardless of the time that elapsed after diagnosis.

According to Saegrove et al. and Coreil et al., breast cancer patients prefer the company of people with similar problems [24, 25]. This accounts for the popularity of support groups in Poland and in other countries. Such groups help breast cancer patients starting from the moment of diagnosis [21]. Owing to the technological advancement, support groups can function in various forms - through the Internet and teleconferences [26-28].

Our study had a non-randomized, cross-sectional design and had limitations. It was carried out in a small group and its results cannot be generalized for the entire population. We did not assess personality traits. It would be interesting to know whether members of Amazon groups develop the traits that promote better quality of life or whether they already have them before they enter these support groups. Information regarding the type of oncological treatment was obtained during the study directly from patients; due to the character of the study we were unable to access relevant medical records.

This was a major limitation of the study. Another limitation of our research consisted in the character of survey collection. Participants at Amazon Clubs were surveyed during club meetings while patients not affiliated with any club were surveyed during their follow-up visits at the Oncology Centre. Although the investigators did their best to ensure comfortable atmosphere of the meeting, the very fact of having to report at hospital and undergo a follow-up visit might be a source of stress for responders. It would be worthwhile to prospectively study patient outcomes depending on their personality types. Based on the work of other authors, women who receive psychological support have improved functioning during and after breast cancer treatment [29]. The physical activity of women after mastectomy is reduced. This may lead to the adverse event like body postural changes and limited range of motion [30-33]. Moreover, membership in support groups induces an optimistic attitude [34].

In conclusion, breast cancer patients who are members of Amazon groups have a better quality of life after completion of treatment in comparison to similar patients who are not members of such groups. This also applies to patients who received the diagnosis more than 5 years earlier. In this study, we confirmed that support groups play an important role in well-being of breast cancer patients. Members of Amazon groups had better emotional functioning, body image, life perspectives and general quality of life as well as a lower tendency towards destructive coping strategies in comparison to the control group. Our research suggests that breast cancer patients require environmental support regardless of the time that elapsed after diagnosis. Self-support groups provide breast cancer patients with the opportunity to both receive and provide help, which creates a feeling of being useful.

\section{The authors declare no conflict of interest.}

\section{References}

1. Wonghongkul T, Dechaprom N, Phumivichuvate Losawatkul S. Uncertainty appraisal coping and quality of life in breast cancer survivors. Cancer Nursing 2006; 29: 250-7.

2. Johansson M, Rydén A, Finizia C. Mental adjustment to cancer and its relation to anxiety, depression, $\mathrm{HRQL}$ and survival in patients with laryngeal cancer - a longitudinal study. BMC Cancer 2011; 11: 283.

3. Thome B, Hallberg IR. Quality of life in older people with cancer a gender perspective. Eur J Cancer Care 2004; 13: 454-63.

4. The World Health Organisation quality of life assessment (WHOQOL). Position paper from the world health organisation. Soc Sci Med 1995; 41: 1403-9.

5. Bonnema J, van Wersch A, van Geel AN, Pruyn JF, Schmitz PI, Paul MA, Wiggers T. Medical and psychosocial effects of early discharge after surgery for breast cancer: randomised trial. Br Med J 1998; 316: 1267-71.

6. Thorsen L, Gjerset GM, Loge JH, Kiserud CE, Skovlund E, Fløtten T, Fosså SD. Cancer patients' needs for rehabilitation services. Acta Oncol 2011; 50: 212-22.

7. de Boer AG, Taskila T, Ojajärvi A, van Dijk FJ, Verbeek JH. Cancer survivors and unemployment: A meta-analysis andmeta-regression. JAMA 2009; 301: 753-62.

8. King MT, Kenny P, Shiell A, Hall J, Boyages J. Quality of life three months and one year after first treatment for early stage breast cancer: influence of treatment and patient characteristics. Qual Life Res 2000; 9: 789-800.

9. Uzun O, Aslan F.E, Selimen D, Koç M. Quality of life in women with breast cancer in Turkey. J Nurs Scholarsh 2004; 36: 207-13.

10. Alfano CM, Rowland JH. Recovery issues in cancer survivorship: a new challenge for supportive care. Cancer J 2006; 12: 432-43.

11. Ashing-Giwa KT, Padilla G, Tejero J, Kraemer J, Wright K, Coscarelli A, Clayton S. Understanding the breast cancer experience of women: a qualitative study of African American, Asian American, Latina and Caucasian cancer survivors. Psycho-Oncology 2004; 13: 408-28.

12. Lam WW, Fielding R. The evolving experience of illness for Chinese women with breast cancer: a qualitative study. Psychooncology 2003; 12: 127-40.

13. Wani SQ, Khan T, Teeli AM, Khan NA, Wani SY; Ashfaq-ul-Hassan. Quality of life assesment in survivors of breast cancer. J Cancer Res Ther 2012; 8: 272-6.

14. Ganz PA., Desmond KA, Leedham B, Rowland JH, Meyerowitz BE, Belin TR. Quality of life in long-term, disease-free survivors of breast cancer: a follow-up study. J Natl Cancer Inst 2002; 94: 3949.

15. Bradley CJ, Oberst K, Schenk M. Absenteeism from work: the experience of employed breast and prostate cancer patients in the months following diagnosis. Psychooncology 2006; 15: 739-47.

16. Bukovic D, Fajdić J, Hrgović Z, Kaufmann M, Hojsak I, Stancerić T. Sexual dysfunction in breast cancer survivors. Oncology 2005; 28 : 29-34.

17. Al-Azri M, Al-Awisi H, Al-Moundhri M. Coping with a diagnosis of breast cancer-literature review and implications for developing countries. Breast Journal 2009; 15: 615-22.

18. Geer S, Morris T, Pettingale K. Psychological response to breast cancer diagnosis: effect on outcome. Lancet 1979; 13: 785-7. 
19. Osborne RH, Sali A, Aaronson NK, Elsworth GR, Mdzewski B, Sinclair AJ. Immune function and adjustment style: do they predict survival in breast cancer? Psychooncology 2004; 13: 199-210.

20. Stang I, Mittelmark MB. Intervention to enhance empowerment in breast cancer self-help groups. Nursing Inquiry 2010; 17: 47-57.

21. Ussher J, Kirsten L, Butow P, Sandoval M. What do cancer support groups provide which other supportive relationships do not? The experience of peer support groups for people with cancer. Soc Sci Med 2006; 62: 2565-76.

22. Björneklett $H$, Lindemalm C. A randomized controlled trial of a support group intervention on the quality of life and fatigue in women after primary treatment for early breast cancer. Support Care Cancer 2012; 20: 3325-34.

23. Dunn J, Steginga SK, Occhipinti S, Wilson K. Evaluation of a peer support program for women with breast cancer-lessons for practitioners. J Commun Appl Soc Psychol 1999; 9: 13-22.

24. Saegrov S, Halding AG. What is it like living with the diagnosis of cancer? Eur J Cancer Care 2004; 13: 145-53.

25. Coreil J, Wilke J, Pintado I. Cultural models of illness and recovery in breast cancer support groups. Qual Health Res 2004; 14: 905-23.

26. O'Brien M, Harris J, King R, O'Brien T. Supportive-expressive group therapy for women with metastatic breast cancer: improving access for Australian women through use of teleconference. Counsell Psychother Res 2008; 8: 28-35.

27. Han JY. A longitudinal study of use of an interactive health communication system. Health Communication 2012; 29: 319-30.

28. Shaw B, Hawkins RP, McTavish F, Pingree S, Gustafson D. Effects of insightful disclosure within computer mediated support groups on women with breast cancer. Health Communication 2006; 19: 133-42.

29. Classen C, Butler LD, Koopman C, Spiegel D. Supportive-expressive group therapy and distress in patients with metastatic breast cancer: a randomized clinical intervention trial. Arch Gen Psychiatry 2001; 58: 494-501.

30. Głowacka I, Nowikiewicz T, Siedlecki Z, Hagner W, Nowacka K, Zegarski W. The assessment of the magnitude of frontal plane postural changes in breast cancer patients after breast-conserving therapy or mastectomy - follow-up results 1 year after the surgical procedure. Pathol Oncol Res 2016; 22: 203-8.

31. Głowacka I, Nowikiewicz T, Hagner W, Nowacka K, Sowa M, Zegarski W. Sagittal plane postural changes in female patients with breast cancer after different surgical techniques. Breast J 2017; 23: 109-11.

32. Głowacka-Mrotek I, Sowa M, Siedlecki Z, Nowikiewicz T, Hagner $W$, Zegarski W. Evaluation of changes to foot shape in females 5 years after mastectomy: a case-control study. Breast Cancer Res Treat 2017; 163: 287-94.

33. Kozak D, Głowacka-Mrotek I, Nowikiewicz T, Siedlecki Z, Hagner W, Sowa M, Analysis of undesirable sequelae of sentinel node surgery in breast cancer patients - a prospective cohort study. Pathol Oncol Res 2017;. doi: 10.1007/s12253-017-0306-3.

34. Giese-Davis J, Koopman C, Butler LD, Classen C, Cordova MJ, Fobair P, Benson J. Change in emotion regulation strategy for women with metastatic breast cancer following supportive-expressive group therapy. J Consult Clin Psychol 2002; 70: 916-25.

\section{Address for correspondence}

Iwona Głowacka-Mrotek

Marii Curie-Skłodowskiej 9

85-094 Bydgoszcz, Poland

$\mathrm{fax}+48525854042$

tel. +48791225318

e-mail: iwona.glowacka@cm.umk.pl

Submitted: 24.10 .2017

Accepted: 8.12 .2017 